\title{
Assessing Attachment with the Bird's Nest Drawing: A Review of the Research
}

\author{
Donna H. Kaiser, New Haven, CT, and Sarah Deaver, Norfolk, VA
}

\begin{abstract}
The Bird's Nest Drawing (Kaiser, 1996) is an art-based assessment that was developed to assess attachment security. In the past 10 years, several studies have further tested this art therapy directive with various populations. This paper briefly reviews attachment theory, delineates the significant findings from five of the studies, and provides information from four others. Implications for clinical use of the Bird's Nest Drawing and need for future research are discussed.
\end{abstract}

\section{Introduction}

The Bird's Nest Drawing (BND) was conceived as an art-based assessment that would provide information about an individual's attachment security as depicted in a drawing (Kaiser, 1996). Unlike other art therapy assessments that are tied to atheoretical classification systems such as the Diagnostic and Statistical Manual (American Psychiatric Association, 1994), the BND is grounded in attachment theory and seeks to access a person's internal representation of self and other. The BND provides useful clinical information about a client's attachment security, which affects the development of a therapeutic relationship and the course of art therapy treatment. In the past 10 years, five research studies conducted at the Eastern Virginia Medical School in Norfolk have further tested this art therapy directive with various populations. This article briefly reviews attachment theory, delineates the significant findings from the five studies, and identifies four other studies on the BND. Implications for clinical use of the BND and need for future research are discussed.

\section{Attachment Theory}

Attachment theory is a developmental and relational framework with origins in psychoanalytic and object relations theories. Bowlby (1969/1982) selected the term "attachment" to direct attention to the importance of intimate relationships throughout a person's life. Based on his clinical observations and study of ethology - the science that explains animal behavior - Bowlby surmised that just

Editor's note: Donna Kaiser, PhD, ATR-BC, LPC, LMFT, is Assistant Professor of Psychology, Albertus Magnus College, New Haven, CT. Sarah Deaver, MS, MS Ed, ATR-BC, is Associate Professor and Research Director, Graduate Art Therapy Program, Eastern Virginia Medical School, Norfolk, VA. Correspondence concerning this article may be addressed to the first author at dkaiser@albertus.edu as baby monkeys preferred to snuggle with a cloth mother even though a wire mother supplied milk, and baby goslings followed whatever figure they were attached to during a critical time period (referring to the research of Harlow and Lorenz, respectively), human infants instinctively preferred to remain near protective caretakers to ensure survival. Bowlby (as cited in Bretherton \& Munholland, 1999) asserted that:

Human beings of all ages are found to be at their happiest and to be able to deploy their talents to best advantage when they are confident that, standing behind them, there are one or more trusted persons who will come to their aid should difficulties arise. The person trusted provides a secure base from which his (or her) companion can operate. (p. 89)

The basic premise of attachment theory is that humans innately seek proximity to parents and primary caretakers in order to feel safe and secure (Bowlby, 1969/1982). Based on their early experiences with these attachment figures, children develop certain behaviors to elicit desired responses (Karen, 1998). Over time, these interactions are internalized as mental representations of relational experiences, or internal working models (IWMs) of attachment. IWMs include beliefs and expectations regarding the lovability and worth of the self and the availability of the caregiver, as well as various rules governing regulation of attachment-salient affects and behaviors (Mayseless, 1996). Contained in the IWM are the core beliefs an individual holds - either positive or negativeabout the self, others, and the world (Levy \& Orlans, 1998). Attachment theory also postulates that a person's IWM of attachment provides a template for relationship patterns throughout life.

Simpson and Rholes (1998) emphasized that Bowlby's theory addresses both normative and individual differences in attachment behaviors. The normative component explains attachment behavior as species-typical and developmentally stage-like, meaning that all humans tend to evolve in a similar manner with respect to their needs for attachment. The individual difference component explains variations from modal secure behavior in terms of characteristic behaviors, feelings, and cognitions. When caregivers have been inconsistently available, absent, rejecting, or abusive, a less than optimal secure base experience may develop and the child's IWM is likely to be insecure. Research has delineated three categories of insecurity in children: avoidant, ambivalent (earlier referred to as resistant), and disorganized/disoriented; it also posits three cat- 
egories of insecurity in adults: dismissing, preoccupied, and fearful. These categories diverge because research on attachment classification in children and adults has evolved from different disciplines.

The IWMs of securely attached people include a basic trust in attachment figures and confidence that others will be available, responsive, and helpful should adverse or stressful situations arise (Karen, 1998). Secure individuals are confident in their explorations of the world and are able to rely on themselves as well as turn to others for support. Insecure attachment is associated with various problems a person may experience in regulating emotions, including most commonly either a defensive denial of feelings or a pronounced and intense emotional arousal. Individuals with insecure attachment expect a negative response from others regarding their needs for comfort; thus, they are unable to manage distress or to effectively seek support. For a therapist, understanding a client's attachment security is useful in determining the level of trust the client brings to the therapeutic relationship, as well as likely expectations about treatment.

Much research on establishing attachment classification has been conducted in developmental psychology. Of particular interest to art therapists is the research of Kaplan and Main (1986), who studied representations of attachment security in children's art. The researchers studied family drawings created by kindergarten children as predictors of secure or insecure attachment category. They developed a classification system for coding a sample of children's family drawings that matched, with $76 \%$ accuracy, their Strange Situation classifications. The Strange Situation is a well-known, valid, and reliable behavioral procedure for classifying attachment in children who are up to 18 months old (Ainsworth, Blehar, Waters, \& Wall, 1978). Results demonstrated that children who were classified as secure tended to depict family members as individuated (e.g., each figure showing individual differences in facial expression) and in relatively close proximity to one another. Children classified as avoidant tended to draw family members with almost identical happy expressions that imparted a superficial or false quality to the image (Kaplan \& Main, 1986). These figures were often depicted with missing arms or other features that were incongruent with the smiling faces. Children with ambivalent attachment drew either very small or very large figures that often overlapped one another. These images tended to impart a highly vulnerable quality, such as parental figures crowding the paper space and figures with exaggerated soft body parts (e.g., stomachs, navels, and nostrils). The drawings of children with disorganized attachment were similar in some ways to the other three categories but differed in overall impression. These drawings were characterized by foreboding, irrational, and/or disorganized features. Also, strange marks, unfinished objects or figures, partially scratched out areas, and superficially cheerful elements (e.g., hearts and rainbows) were included but not integrated into the overall composition.

Others have continued the study of children's drawings as predictors of attachment security (Fury, Carlson, \&
Sroufe, 1997; Madigan, Ladd, \& Goldberg, 2003; Pianta, Longmaid, \& Ferguson, 1999; Silver, 2005). These authors have largely concluded that the more global the approach to rating the drawings the stronger the link to attachment category. A global approach involves a more holistic and impressionistic evaluation of a drawing than simply comparing specific indicators or elements of the drawing to a validated instrument. For example, Fury et al. (1997) analyzed children's family drawings in four different ways: by examining the presence or absence of specific drawing indicators, by using global rating scales, and by asking raters to classify drawings into attachment categories. The researchers found that global rating scales were most successful in predicting attachment classification. Madigan et al. (2003) used a similar approach and also found that global scales were more successful in predicting attachment classification than specific drawing indicators, rater classifications, or clinical methods derived from rater manuals.

\section{The Bird's Nest Drawing}

The Bird's Nest Drawing (BND) was inspired by research on family drawings by Kaplan and Main (1986) and a study by Lieberman, Weston, and Pawl (1991) that investigated therapeutic interventions to alter the attachment patterns of insecure mothers and their infants. The BND is a projective drawing task developed to assess an individual's attachment security (Kaiser, 1996). It is what Neale and Rosal (1993) characterized as idiosyncratic to art therapy: a projective drawing task that is used to assess particular problems (in this case, attachment security) and provide valuable clinical information that informs art therapy treatment.

Kaiser had the original intent of creating a directive that was less threatening than a family drawing, which Kwiatkowska (1978) described as anxiety-provoking for some individuals. After considering several possible tasks, Kaiser observed that the BND directive was most likely to invite projection of attachment-related themes. In addition, she found that many people who contributed drawings for a pilot study seemed to prefer this directive over others tested, possibly because of the emotional distance and ease of depicting the common image of a bird's nest. Kaiser found that the symbolic imagery of a bird's nest supplies information relevant to security:

The depiction of a bird's nest, initially perceived as an innoc-
uous task by most people, often yields rich associations about
the contents of the nest, the physical nature of the nest form,
the absence or presence of nurturing figures, and the fate of
eggs or baby birds drawn or omitted. (1996, p. 333)

\section{Research on the BND}

When the BND was initially developed, certain methodological issues involved in the attachment classification of various populations existed. At the time of the first study (Kaiser, 1996), there were few measures available to determine attachment security; thus, a scale yielding a range of scores instead of attachment categories was used to establish more-secure and less-secure participant groups. 
Since then, "working models of romantic relationships" (Shaver \& Mikulincer, 2002, p. 243), more commonly known as attachment styles in adults, have been developed from self-report measures (Feeney, 1999). Two art therapy BND studies with adults (Francis, Kaiser, \& Deaver, 2003; Overbeck, 2002) used the Relationship Questionnaire ([RQ] Bartholomew \& Horowitz, 1991), which identifies four attachment styles. There is an adolescent version of the RQ as well, which was used in one study on the BND (Trewartha, 2004). Hyler's (2002) study used family drawings and the procedures developed by Kaplan and Main (1986) as the basis for establishing attachment categories for the children.

As previously stated, research on attachment classification in children and adults has evolved from different disciplines and research methods and thus the categories referenced in these studies are somewhat different. With children, attachment is described in terms of classifications (secure, insecure avoidant, insecure ambivalent, and insecure disorganized), whereas adult attachment is described in terms of relationship styles (secure, dismissing-avoidant, preoccupied, and fearful-avoidant). The latter are roughly comparable to the classifications for children, though defined differently. The studies reviewed below were conducted with various populations and are presented in chronological order of completion. Each study provided data for the current form of the measure that is being developed.

\section{Kaiser}

In the first study of the Bird's Nest Drawing (Kaiser, 1996), Kaiser collected BNDs from a sample of mothers $(N=41)$. Using the Attachment to Mother (ATM) scale of the Inventory of Parent and Peer Attachment (IPPA) (Armsden \& Greenberg, 1987) and a median split technique, participants were divided into a more securely attached group (High; $n=20$ ) and a less securely attached group (Low; $n=21$ ). The ATM assesses an individual's attachment to his or her own mother. BNDs were rated for the presence or absence of nine hypothesized indicators of attachment. There were no statistically significant correlations between ATM scores and these hypothesized indicators, although there were interesting statistical trends. Participants from the Low-ATM group tended to draw nests without bottoms, $r(40)=.27, p=.08 ; r^{2}=.07$, or tilted nests that would be unable to contain the nest contents, $r(40)=.26, p=.07 ; r^{2}=.07$.

The BNDs collected for the study frequently included images of parent and/or baby birds. In post hoc analyses of these drawings, new raters scored the BNDs for the presence or absence of baby birds, parent birds, and eggs. The results indicated that the High-ATM group included birds in their drawings significantly more often than the LowATM group, $\chi^{2}(1, N=41)=7.04, \mathrm{p} \leq .01 ; \Phi=.32$. Figure 1 is a BND from the Low-ATM group and shows a tilted nest without birds; in contrast, Figure 2, from the HighATM group, includes birds.

Kaiser also observed that the BNDs of the more securely attached group had a whimsical, happy quality

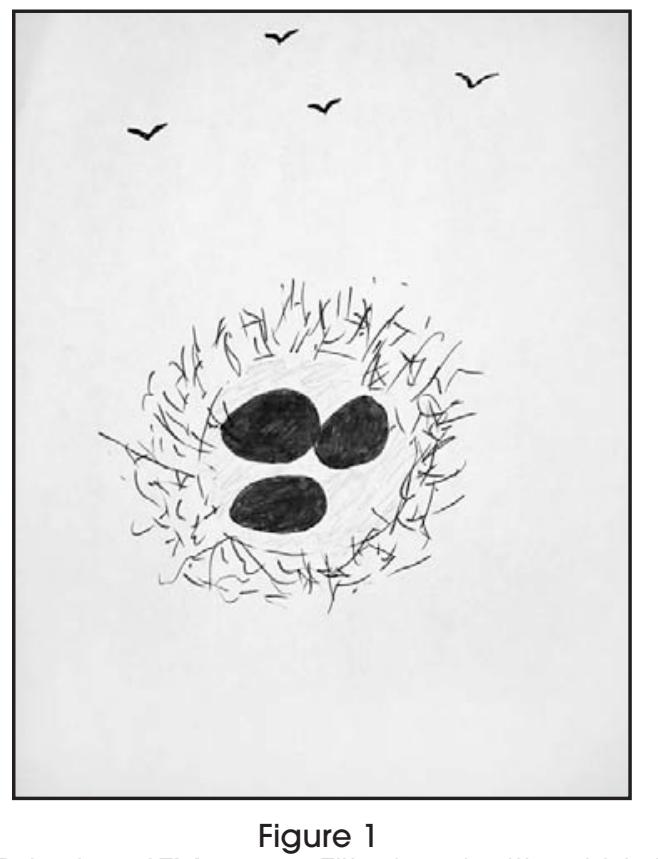

BND by low ATM scorer: Tilted nest without birds.

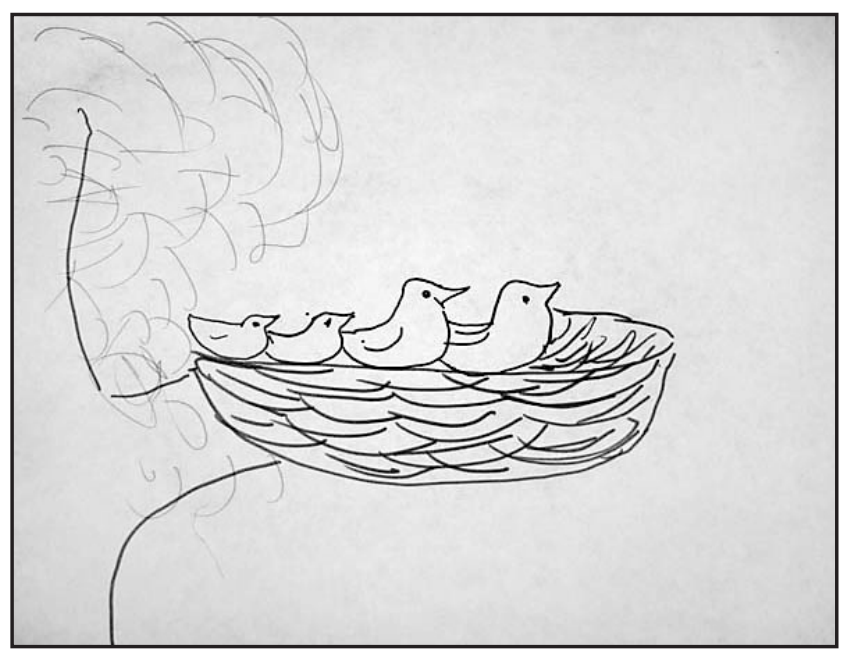

Figure 2 BND by high ATM scorer: Birds included.

and that participants composed titles for their drawings that could be described as engaging or gently humorous. This important feature suggested that the data collection could be expanded in subsequent research to include stories about the drawings. Limitations of the study included the small volunteer sample, the exploratory nature of the drawing indicators tested, and the use of a self-report to determine whether group participants were more or less securely attached. Although limited, this preliminary study provided the groundwork for subsequent research.

\section{Francis, Kaiser, and Deaver}

Using Kaiser's original indicators and additional ones observed in clinical work, Francis, Kaiser, and Deaver (2003) studied the BNDs of adults with substance abuse (SA) disorders. They hypothesized that individuals with SA 
disorders $(n=43)$ would depict BNDs differently than patients in a comparison group from a medical clinic who had no known substance abuse disorders $(n=27)$, and that the BNDs would reflect the various attachment styles of those in the SA group. In terms of the latter hypothesis, the researchers wanted to examine whether it was possible to distinguish between the drawings of those with different attachment styles within the SA group, given that Kaiser's (1996) study only examined differences between higher and lower attachment groups. Participants completed a BND, a story about their BND, and Bartholomew and Horowitz's (1991) Relationship Questionnaire. Because the drawing titles from more securely attached mothers in Kaiser's study suggested positive associations to the nest image, the researchers collected stories to acquire additional projective data for assessing attachment.

Participants in the SA group were more likely to have an insecure attachment style and to use fewer colors in their BNDs than participants in the control group, $\chi^{2}(1$, $N=70)=7.04, p<.01 ; C=.30$. The control group, comprised primarily of participants with secure attachment style, was significantly more likely to feature green as the predominant color, $\chi^{2}(1, N=70)=9.13, p<.01 ; C=.33$, and to include birds drawn in the nest, $\chi^{2}(1, N=70)=$ $3.25, p=.07 ; \Phi=.22$. The SA group most often depicted the nest tilted or viewed from above, $\chi^{2}(1, N=70)=2.93$, $p=.08 ; \Phi=.20$. These trends are consistent with Kaiser's finding that more secure participants included birds and less secure participants drew nests that were tilted. Because there were too few individuals with ambivalent attachment in the SA group, criteria for chi-square analysis were not met; thus the second hypothesis was not tested.

Content analysis of the stories revealed five themes: family, nature and renewal of life, food or hunger, abandonment, and environments of personal significance (Francis et al., 2003). These themes suggested the presence of conscious and unconscious material related to individuals' family and intimate relationship dynamics. Family themes appeared in the stories of participants of all attachment styles, whereas stories about the wonder of nature were written more often by participants with secure attachment. Themes of aggression and anger were often combined with themes of family and food in stories provided by those in the SA group.

Kaiser recently conducted a secondary analysis of this study's data that combined attachment categories across both the SA group and the control group in order to meet the criteria for chi-square analysis for examining indicator differences among the four attachment styles. Results of this analysis provide additional evidence about indicators in the BNDs of secure individuals. In the secure group the following indicators were significant: birds drawn, $\chi^{2}(1, N$ $=70)=16.85, p<.001 ; C=.44$; entire bird family drawn, $\chi^{2}(1, N=70)=6.81, p<.01 ; C=.30$; use of four or more colors, $\left.\chi^{2}(1, N=70)=18.82, p<.001 ; C=.46\right)$; nest drawn in profile (not tilted), $\chi^{2}(1, N=70)=4.18, p<.05$; $\mathrm{C}=.24$; and green as the dominant color, $\chi^{2}(1, N=70)=$ $10.55, p<.01 ; C=.36$.

Despite the limitations of the restricted sample size and an extensive rating process, this study extended the

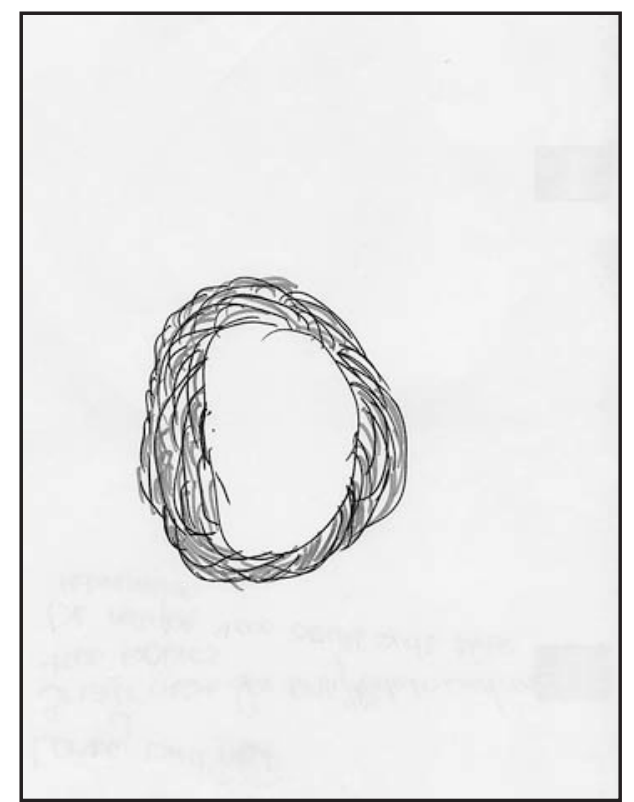

Figure 3 BND by high $R Q$ scorer: BND and story are incongruent with secure attachment

research to a clinical population, supported previous findings about indicators in secure BNDs, and supplemented the data with stories that revealed attachment-related themes. This study pointed to the utility of including three methods to access attachment security in future validity research: the BND, a story, and a self-report.

\section{Overbeck}

Overbeck (2002) researched the Bird's Nest Drawings of a high-risk sample of pregnant women $(N=32)$. Risk factors included low to moderate socioeconomic status, lack of stable partner relationships, and a high percentage of current unplanned pregnancies. Methodology replicated the Francis et al. (2003) study except that the BND Checklist (Kaiser, 2001), an improved and shorter instrument, was used to rate the drawings. There were no statistically significant relationships between BND indicators and attachment style. Many of the women who self-identified as secure on the Relationship Questionnaire drew BNDs that suggested insecure attachment, and told stories that also pointed to insecure attachment. Overall, these women used minimal paper space for their drawings, did not include an environment for the bird's nest in the drawing, and used little color. For example, Figure 3 was created by a participant who identified as secure on the RQ but provided this story: "Lonely bird's nest... [a] small nest for only one adult bird and two babies..." Thus the drawing and story were not consistent with secure attachment.

In Overbeck's study, most of the themes that emerged in the BND stories were consistent with those from the Francis et al. (2003) study: home and family, food or hunger, and abandonment. New themes emerged as well: eggs, comments on poor drawing ability, and the tendency to give a brief drawing description instead of a story. However, most themes were incongruent with participants' 


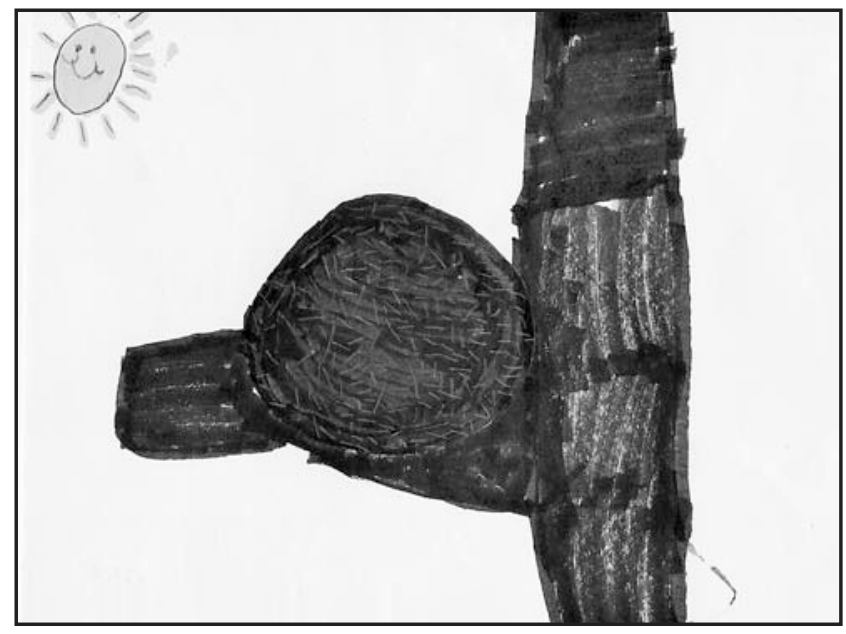

Figure 4

BND by insecure ambivalent child: Brown color is dominant and strokes are dark and overlapping

self-reports of secure attachment. Although the participants were pregnant, the theme of renewal of life-an expected response from this population and one that was noted in the Francis et al. study-did not appear.

A useful finding from this study was the emergence of BND story themes about poor drawing ability and the frequency with which participants described their drawings instead of providing a story. These approaches to the story suggested a level of defensiveness around drawing, which could explain the incongruence of the BND and self-reported secure attachment style. As a whole, these data point to the need for nondefensive measures of attachment such as the Bird's Nest Drawing and the accompanying story.

\section{Hyler}

Hyler's (2002) study on elementary school children's Bird Nest Drawings presented interesting methodological problems because there was no easy way (e.g., self-reports) to determine categories of secure or insecure attachment. This problem was addressed by rating the children's family drawings according to Kaplan and Main's (1986) manual. Raters of the family drawings had to be knowledgeable of attachment theory and the four attachment categories, and had to be trained to use the manual. Although difficult and time-consuming, this system previously demonstrated preliminary reliability and validity for determining attachment categories (see Fury et al., 1997; Madigan et al., 2003). Family drawings were used to establish the attachment classifications for the children, aged 9 to 11 years $(N=49)$, as either secure $(n=13)$, insecure avoidant $(n=14)$, insecure ambivalent $(n=14)$, or disorganized $(n=8)$. These four attachment classifications were then compared to indicators rated according to the BND Checklist (Kaiser, 2001).

Chi-square analysis indicated that children with secure attachment used green as the dominant color in their BNDs significantly more often than the other participants, $\chi^{2}(1, N=49)=6.5, p=.034 ; C=.34$. No other indicators reached statistical significance but, interestingly, 86\% of the children who were classified as ambivalent drew a tree to support the bird's nest. Examination of these BNDs revealed that the trees depicted had two features that could be important for classifying this group. The first was that nests were drawn in vulnerable positions: they balanced on branches that seemed too weak to support them, perched precariously on the ends of limbs, or otherwise were depicted in an exposed manner. This observation seemed to parallel the vulnerable quality of ambivalently attached children's family drawings described by Kaplan and Main (1986). Secondly, the dominant color used in this group of drawings was brown, applied using heavy pressure that resulted in dark overlapping strokes (see Figure 4).

Despite limitations of the small sample size and a difficult classification process, Hyler's study extended BND research to children, provided confirming data on green as the dominant color in BNDs of secure individuals, and provided new data on specific characteristics of BNDs drawn by insecure ambivalent children that could be tested in future research. In addition, the study led us to rethink procedures for determining attachment categories and to consider evaluating the drawings qualitatively as well as by groupings of indicators, which Kaplan and Main (1986) had done with family drawings. This consideration was incorporated into data analysis in the next study.

\section{Trewartha}

Trewartha (2004) studied the Bird's Nest Drawings of a small sample of adolescents in foster care $(N=14)$. Participants completed the BND, provided both a title and story, and completed the Adolescent Relationship Questionnaire (Scharfe, 1999), an adolescent version of the RQ that has an internal check for discrepancy on the self-report. Less than half $(43 \%)$ of the participants identified themselves as secure, whereas the remainder rated themselves as fearful, preoccupied, or dismissing. The internal check indicated that 4 participants were inconsistent in their ratings.

BND ratings were conducted in two ways. First, using groupings of indicators from previous BND research, trained raters qualitatively evaluated the drawings and assigned each to an attachment category. Eight of the rater's evaluations matched participant self-ratings and six did not. In the second analysis, raters used a slightly revised version of the BND Checklist (Kaiser, 2001). However, the small sample size did not meet criteria for chi-square analysis using four categories, so the sample was divided into secure and insecure (combining fearful, preoccupied, and dismissing) groups. Although one indicator reached significancedrawing nests off center by those identifying as secure-little can be concluded due to the extremely small sample size. Furthermore, due to the nature of the sample, it is doubtful that even $43 \%$ of participants actually had secure attachment, thus, these results may be congruent with what was found in Overbeck's (2002) study; that is, there may have been a defensive process that produced the responses to the self-report used to classify attachment.

Few indicators of security were seen in the BNDs of these adolescents in foster care. No drawings were qualitatively rated as giving an impression of happiness; an envi- 
ronment surrounding the nest was depicted only once and 11 participants drew nests floating on the page (no environment and no support). Only one participant used green as the dominant color, the indicator found in secure drawings in two previous studies. As in Overbeck's (2002) study, most of these drawings appeared impoverished and were completed with minimal investment. For example, participants used very little paper space (thus leaving a great deal of empty space) and a general lack of color was evident, with several participants exclusively using pencil or pencil and brown marker. More than $70 \%$ of the BNDs included no birds. Drawings with birds depicted solitary baby birds; no parental birds were present in any drawings. Considering the fact that the participants were in foster care, these findings are congruent with Kaiser's (1996) conclusion that BNDs without birds may indicate insecure attachment. The findings also supported the conclusions of Francis et al. (2003) that BNDs of secure individuals tend to feature green as the dominant color. The study affirmed that examining overall impression and the inclusion of an environment or a support for the nest were important aspects to consider when evaluating BNDs.

Content analysis of the stories resulted in six themes, five of which were congruent with previous research (abandonment, renewal of life, stories of personal experience, concerns about drawing ability, and drawing description in lieu of a story). A theme unique to this sample was that of waiting. Example phrases associated with this theme were "waiting for a bird to come lay some eggs" and "waiting for something to do" (Trewartha, 2004, p. 50). Kaiser has consistently observed the theme of "waiting" in titles provided by individuals with ambivalent attachment.

This study extended Bird's Nest Drawing research to adolescents in foster care and provided additional support for the use of stories in addition to drawings and selfreports to assess attachment. Results from Overbeck and Trewartha suggest that, as in the case of individuals who may desire to appear healthier or more positive to the examiner, the use of a self-report may not always provide a valid measure of attachment security.

\section{Other Studies}

Additional research has been conducted by at least four graduate art therapy students in other universities and are included in this review because some of their findings and observations are consistent with the studies we report above. However, they are only briefly described because, except for Reyes (below), the studies' small sample sizes do not allow for firm conclusions to be generalized.

Reyes (2002) tested the validity of the BNDs of a sample of college students $(N=76)$ in comparison with three subscales of the Inventory of Parent and Peer Attachment (IPPA). Of a large number of analyses conducted, two indicators were found to be significant when compared to the Attachment to Peer subscale: nests that were not tilted and use of four or more colors. Unfortunately, she did not indicate whether they were associated with the more or less secure group. Reyes commented that many of the drawings featured brown as the dominant color and that most of them included eggs but no birds.

Fine (2002) studied hospitalized adolescents diagnosed with anorexia $(N=14)$ and also compared BND indicators with the IPPA. No drawing indicator from the BND Checklist (Kaiser, 2001) was statistically related to the IPPA scales and Fine concluded that this finding was most likely due to the small sample size. She described most of the drawings in her study as using little color, with over one-third drawn in pencil only.

Lenssen (2006) researched the BNDs of adolescents with a history of parental substance abuse $(N=16)$. No statistical analysis was performed because of the small sample size. She stated that half of the participants in her study rated themselves as secure on a self-report, echoing findings from Overbeck and Trewartha. She also observed that none of the drawings used green as the dominant color. In fact, seven or more featured brown as the dominant color.

Sheller (2007) conducted a qualitative phenomenological study of how 4 children (ages 4-11 years) with insecure attachment experienced parental care. She used the BND as well as a Bird's Nest Sculpture (BNS), an art therapy directive she developed for her study, to promote the children's expressions of attachment. Themes of vulnerability, the need for protection, and danger emerged in her analysis. She concluded that the BND and the BNS were valuable for assisting these children in communicating attachment schemas and their perceptions of parental relationships through metaphor.

\section{Conclusion}

This review of a group of studies provides preliminary evidence in support of the use of the Bird's Nest Drawing to assess attachment security. The initial study indicated that the BND might prove useful for assessing attachment and the nature of BND titles cued us to include stories in subsequent research. The addition of the story element provides triangulation and validation of the assessed attachment category. However, as of yet no attempt has been made to systematically determine how story themes might be related to attachment category. In each study new themes emerged in the stories of those with insecure attachment, and each new theme provides valuable clinical information for the use of art therapy with certain clients.

Hyler's (2002) study changed the way we thought about using drawings to assess attachment. Based on our experience using the Kaplan and Main (1986) system for classifying family drawings, we recognized that using general impressions along with groups of indicators is a more valid approach than looking at any single indicator as signifying attachment. Up until now, BND checklists have been tested in an exploratory way and have been modified as each study yielded useful data for discriminating among classifications. Table 1 presents findings from each study that contributed to our evolving understanding of using BNDs to assess attachment. We are using these cumulative data to develop two separate classifying systems: one for children and one for adolescents and adults. We plan to 
continue to test this system with a larger population of college students.

Cumulatively, the studies discussed in this article provide data that inform art therapists' clinical assessment of attachment. By using the BND to assess an individual's mental representations of attachment security, art therapists can better understand clients' internalized conscious and unconscious beliefs, assumptions, and schemas about their selves and relational partners. This is useful both diagnostically and for developing treatment plans to target particular attachment-related symptoms and behaviors.

Two distinct advantages of the BND is that it is a theoretically based art therapy directive and its interpretation examines the drawing's overall impression, its symbolic content, and the formal qualities of an image. In our experience, most of those who complete this directive perceive it as easy, nonthreatening, and quickly accomplished. In contrast to anxious and often reluctant or negative responses to requests for family drawings, many individuals, particularly child clients, have responded with an expression of confidence in their ability to depict a bird's nest. Children also enjoy writing or relating a story about their BND and thereby reveal much information that is useful to art therapists.

As a nonverbal projective, the BND does not incur the methodological problems of self-report measures such as the need for adequate verbal skills, potential defensiveness, or lack of self-awareness. Projective drawing tasks such as

Table 1 Summary of Research and Observational Findings on BND Indicators

\begin{tabular}{|c|c|c|c|}
\hline Category & Indicator & Secure & Insecure \\
\hline \multirow[t]{2}{*}{ Birds } & Birds present & $\begin{array}{l}\text { Kaiser (1996)* } \\
\text { Francis et al. } \\
(2003)^{*} \\
\text { Hyler } \\
(2001)^{* * *}\end{array}$ & \\
\hline & $\begin{array}{l}\text { Entire bird } \\
\text { family }\end{array}$ & $\begin{array}{l}\text { Francis et al. } \\
(2003)^{*}\end{array}$ & \\
\hline \multirow[t]{3}{*}{ Colors } & $\begin{array}{l}\text { Four or more } \\
\text { colors }\end{array}$ & $\begin{array}{l}\text { Francis et al. } \\
(2003)^{*}\end{array}$ & \\
\hline & $\begin{array}{l}\text { Dominant color } \\
\text { green }\end{array}$ & $\begin{array}{l}\text { Francis et al. } \\
(2003)^{*} \\
\text { Hyler }(2001)^{*} \\
\end{array}$ & \\
\hline & \begin{tabular}{|l} 
Dominant color \\
brown
\end{tabular} & & $\begin{array}{l}\text { Hyler } \\
(2001)^{* * *}\end{array}$ \\
\hline \multirow[t]{4}{*}{ Nest } & Nest not tilted & $\begin{array}{c}\text { Francis et al. } \\
(2003)^{*}\end{array}$ & \\
\hline & Tilted nest & & $\begin{array}{l}\text { Kaiser } \\
(1996)^{* *}\end{array}$ \\
\hline & $\begin{array}{l}\text { Nest without } \\
\text { bottom } \\
\text { depicted }\end{array}$ & & $\begin{array}{l}\text { Kaiser } \\
(1996)^{* *}\end{array}$ \\
\hline & Vulnerable nest & & $\begin{array}{l}\text { Hyler } \\
(2001)^{* * *}\end{array}$ \\
\hline
\end{tabular}

the BND also have a distinct advantage over self-reports in that they do not entail difficulties related to social desirability. As seen in two of the studies reviewed (Overbeck, 2002; Trewartha, 2004), self-reports can prove invalid due to a tendency for some participants to misrepresent themselves in order to accentuate their positive image, either deliberately or unconsciously (Feder \& Feder, 1998).

It is our hope that art therapists will consider the clinical value of the Bird's Nest Drawing and conduct further research to test its validity. Future study should be based on a thorough theoretical grounding in attachment theory, should include the BND manuals and scoring system currently in development, and should use methods that build on what we have learned heretofore. Future studies should continue to explore this projective with various clinical populations and gather data on larger samples. Further value could be provided by additional qualitative studies that investigate the client perspective on the merit of this directive as well as art therapists' views of its benefits.

\section{References}

Ainsworth, M. D. S., Blehar, M. C., Waters, E., \& Wall, S. (1978). Patterns of attachment: A psychological study of the strange situation. Hillsdale, NJ: Erlbaum.

American Psychiatric Association. (1994). Diagnostic and statistical manual of mental disorders (4th ed.). Washington, DC: Author.

Armsden, G., \& Greenberg, M. (1987). The inventory of parent and peer attachment: Individual differences and their relationship to psychological well-being in adolescence. Journal of Youth and Adolescence, 16(5), 427-453.

Bartholomew, K., \& Horowitz, L. (1991). Attachment styles among young adults: A test of a four-category model. Journal of Personality and Social Psychology, 61, 226-244.

Bowlby, J. (1969/1982). Attachment. New York: Basic Books.

Bretherton, I., \& Munholland, K. A. (1999). Internal working models in attachment relationships: A construct revisited. In J. Cassidy \& P. R. Shaver (Eds.), Handbook of attachment: Theory, research and clinical applications (pp. 89-111). New York: Guilford Press.

Feder, B., \& Feder, E. (1998). The art and science of evaluation in the arts therapies: How do you know what's working? Springfield, IL: Charles C Thomas.

Feeney, J. A. (1999). Adult romantic attachment and couple relationships. In J. Cassidy \& P. R. Shaver (Eds.), Handbook of Attachment: Theory, research, and clinical applications (pp. 355-377). New York: Guilford Press.

Fine, S. (2002). Towards an improved measure of attachment using the Kaiser Bird's Nest Drawing art based assessment as an indicator of attachment in adolescents with anorexia. Unpublished master's thesis, Notre Dame de Namur University, Belmont, CA. 
Francis, D., Kaiser, D., \& Deaver, S. (2003). Representations of attachment security in the Bird's Next Drawings of clients with substance abuse disorders. Art Therapy: Journal of the American Art Therapy Association, 20(3), 124-137.

Fury, G., Carlson, E. A., \& Sroufe, L. A. (1997). Children's representations of attachment relationships in family drawings. Child Development, 68(6), 1154-1164.

Hyler, C. (2002). Children's drawings as representations of attachment. Unpublished master's thesis, Eastern Virginia Medical School, Norfolk.

Kaiser, D. H. (1996). Indications of attachment theory in a drawing task. The Arts in Psychotherapy, 23(4), 333-340.

Kaiser, D. (2001). Kaiser's Bird's Nest Drawing Checklist. Unpublished manuscript.

Kaplan, J., \& Main, M. (1986). Instructions for the classification of children's family drawings in terms of representation of attachment. Unpublished manuscript, University of California at Berkeley.

Karen, R. (1998). Becoming attached: First relationships and how they shape our capacity to love. New York: Oxford University Press.

Kwiatkowska, H. Y. (1978). Family therapy and evaluation through art. Springfield, IL: Charles C Thomas.

Lenssen, I. (2006). Indicators of attachment insecurity in Bird's Nest Drawings by children of substance abusers. Unpublished master's thesis, Notre Dame de Namur University, Belmont, CA.

Levy, T., \& Orlans, M. (1998). Attachment, trauma, and healing: Understanding and treating attachment disorder in children and families. Washington, DC: Child Welfare League of America.

Lieberman, A. F., Weston, D. R., \& Pawl, J. H. (1991). Preventive intervention and outcome with anxiously attached dyads. Child Development, 62, 199-209.

Madigan, S., Ladd, M., \& Goldberg, S. (2003). A picture is worth a thousand words: Children's representations of family as indicators of early attachment. Attachment and Human Development, 5, 19-37.
Mayseless, O. (1996). Attachment patterns and their outcomes. Human Development, 39, 209-223.

Neale, E. L., \& Rosal, M. L. (1993). What can art therapists learn from the research on projective drawing techniques for children? A review of the literature. The Arts in Psychotherapy, 20(1), 37-49.

Overbeck, L. (2002). A pilot study of pregnant women's drawings. Unpublished master's thesis, Eastern Virginia Medical School, Norfolk.

Pianta, R. C., Longmaid, K., \& Ferguson, J. E. (1999). Attachment-based classifications of children's family drawings: Psychometric properties and relations with children's adjustment in kindergarten. Journal of Clinical Child Psychology, 28(2), 244-255.

Reyes, C. M. (2002). A correlation between the Inventory of Parent and Peer Attachment and the Bird's Nest Drawing as measurements of attachment security. Unpublished master's thesis, Albertus Magnus College, New Haven, CT.

Scharfe, E. (1999). Research tools. Retrieved January 14, 2009, from the Trent University website: http://www.people.tren tu.ca/escharfe/index_files/Page537.htm

Shaver, P. R., \& Mikulincer, M. (2002). Attachment-related psychodynamics. Attachment and Human Development, 4, 133-161.

Sheller, S. (2007). Understanding insecure attachment: A study using children's bird nest imagery. Art Therapy: Journal of the American Art Therapy Association, 24(3), 119-127.

Silver, B. L. (2005). A study of the convergent and discriminate validity of school-aged children's family drawings as a measure of attachment security. Unpublished doctoral dissertation, University of Pittsburgh, PA.

Simpson, J. A., \& Rholes, W. S. (1998). Attachment theory and close relationships. New York: Guilford Press.

Trewartha, S. (2004). Attachment strategies of adolescents in foster care: Indicators and implications. Unpublished master's thesis, Eastern Virginia Medical School, Norfolk. 